\title{
HIDROKONVERSI KATALITIK RESIDU MINYAK BUMI: PENGARUH TEMPERATUR DAN WAKTU REAKSI
}

\author{
Hartiniati $^{*}$
}

\begin{abstract}
Abstrak
Uji terhadap proses hidro-konversi katalitik residu petroleum dari unit refinery Plaju, Palembang dilakukan dengan menggunakan reaktor-batch berpengaduk (autoclave) 1 liter pada kondisi standar: tekanan awal hidrogen $12 \mathrm{MPa}$ dan rasio sulfur terhadap besi $=2.0$. Studi dilakukan untuk melihat pengaruh perubahan temperatur dari 430, 450, dan $470^{\circ} \mathrm{C}$ serta waktu reaksi 30, 60, 90 menit terhadap distribusi produk dan jumlah konsumsi hidrogen. Hasil studi menunjukkan bahwa produk minyak, $\mathrm{CO}, \mathrm{CO}_{2}$ dan hidrokarbon naik secara signifikan dengan naiknya temperatur dan waktu reaksi, namun sebaliknya produk cair bawah (liquid bottom) cenderung turun. Pada kajian ini juga ditemukan bahwa konsumsi hidrogen naik dengan bertambahnya produk minyak, sehingga penggunaan hidrogen lebih efisien. Dengan demikian disimpulkan bahwa proses hidro-konversi katalitik dapat diterapkan pada residue petroleum untuk meningkatkan nilai tambah/kualitasnya.
\end{abstract}

Kata Kunci: Hidrokonversi katalitik; residu minyak bumi

\section{Pendahuluan}

Krisis bahan bakar minyak (BBM) di Indonesia saat ini dapat diprediksi dengan tiga data, yakni: (1) Produksi minyak Indonesia yang terus menurun setelah mencapai puncaknya pada tahun 1980-an; dari hampir 1.6 juta barel/hari, saat ini hanya 1.2 juta barel/hari (2) Pertumbuhan konsumsi energi dalam negeri yang mencapai $10 \%$ per tahun, dan (3) Kecenderungan harga minyak dunia yang terus meningkat setelah krisis moneter yang melanda Asia pada tahun 1998 (Indartono, 2005). Untuk menghindari krisis energi minyak dimasa mendatang, maka upaya pemenuhan kebutuhan energi harus difokuskan pada pencarian dan pemanfaatan sumber energi minyak alternatif yang efisien, ekonomis dan ramah lingkungans sehingga mengurangi peran minyak bumi, dengan menciptakan teknologi yang bersih dan upaya proteksi terhadap lingkungan global.

Salah satu langkah yang dapat ditempuh antara lain dengan meningkatkan kembali kualitas (upgrading) residu dari fraksinasi minyak bumi. Secara umum, tujuan proses up-grading residu minyak bumi adalah untuk mengkonversi hidrokarbon dengan berat molekul besar menjadi minyak sintetis (synthetic crude oil) yang mempunyai berat molekul kecil, dengan titik didih di bawah $525^{\circ} \mathrm{C}$. Konversi ini membutuhkan pemutusan ikatan karbon-karbon dan karbon-sulfur, dan menaikkan rasio atom $\mathrm{H} / \mathrm{C}$ dalam produk, sehingga cocok untuk bahan bakar transportasi seperti minyak solar maupun bensin. Disamping itu juga menghilangkan heteroatom seperti oksigen dan nitrogen, serta sulfur dalam produk yang dihasilkan (Gray, et al, 2002).
Residu minyak bumi merupakan produk samping kilang minyak yang murah dan belum dimanfaatkan secara maksimal. Pada pengilangan minyak mentah diumpankan ke dalam kolom distilasi atmosferik, sehingga menghasilkan beberapa fraksi minyak dengan rentang titik didih yang berbeda. Fraksi ringan dimanfaatkan untuk bahan bakar, sementara fraksi berat (aliran bottom) yang berupa residu, biasanya dijual dengan harga yang sangat murah. Komposisi residu dipengaruhi oleh jenis minyak dan jenis proses pemurnian (refinery) yang digunakan. Jumlah dan sifat residu yang dihasilkan dari tiap minyak mentah akan berbeda.. Berdasarkan strukturnya, senyawa hidrokarbon dalam minyak bumi terbagi atas empat kategori utama, yaitu parafinik, naphtenik, aromatik dan olefin. Ikatan parafin dominan terdapat dalam gasoline dan kerosene (mixed-base petroleum) sedangkan ikatan naftenik dominan terdapat dalam gas oil dan lubricating oil. Sementara itu residu sendiri mengandung komponen naftenik, aromatik, dan hidrokarbon tak jenuh.

Ada beberapa macam teknologi dasar yang dapat digunakan untuk up-grading residu sehingga dihasilkan minyak dengan kualitas yang lebih baik, yaitu konversi termal, konversi katalitik dan konversi hidro (Gray, et al, 1994).

Konversi thermal atau Coking merupakan proses pemecahan molekul-molekul hidrokarbon berat dan panjang dengan menggunakan panas. Proses ini biasanya disebut perengkahan (cracking) karena molekul hidrokarbon yang besar dapat direngkah atau dipecah menjadi molekul-molekul yang lebih kecil. Coking adalah sebuah proses pemecahan intensif secara termal. Proses coking ini digunakan dalam up-

\footnotetext{
$\left.{ }^{*}\right)$ Pusat Teknologi Pengembangan Sumberdaya Energi, BPPT 
grading residu menjadi senyawa-senyawa yang lebih ringan seperti refineable hydrocarbon (naptha, kerosen dan minyak diesel) dan konsentrat karbon yang disebut kokas. Kokas merupakan by product (hasil samping) dari proses coking.

Konversi katalitik (catalytic conversion) merupakan cara lain untuk memecah molekul-molekul hidrokarbon berat (residu) menjadi hidrokarbon lebih kecil atau sulingan (distillate). Oleh karena prosesnya berlangsung pada temperatur tinggi, catalytic conversion benar-benar merupakan bentuk konversi tertinggi secara termal. Pada beberapa proses, hidrogen bertekanan tinggi ditambahkan dalam proses catalytic cracking. Proses demikian dinamakan hydroprocessing. Catalytic conversion lebih mahal dibanding dengan thermal conversion, tetapi menunjukkan hasil yang lebih baik dibanding produk penyulingan biasa.

Pemilihan proses konversi hidro terkait erat dengan tujuan untuk memaksimalkan produk sulingan dan meminimasi produk samping khususnya kokas. Dalam proses ini, reaksi yang terjadi lebih komplek dibanding proses termal dan/atau proses katalitik. Reaksi dari fraksi residu petroleum melibatkan sejumlah reaksi simultan antara senyawa yang berbeda. Tahapan reaksi adalah sebagai berikut: (1) Perengkahan termal dari masing-masing grup dan rantai samping, meninggalkan inti naptenik-aromatis. Perengkahan dari fase awal ini dapat mencapai konversi residu 55-65\%. (2) Dengan adanya hidrogen, hidrogenolisis secara gradual akan mendegradasi grup aromatis menjadi produk distilat dan gas. Katalis akan meningkatkan reaksi hidrogenolisis dengan menghasilkan hidrogen radikal (3) Dalam kondisi inert, reaksi kondensasi akan mendominasi, dan produk utama yang terjadi adalah padatan (Stanford, 1993).

Beberapa faktor yang mempengaruhi proses hidrokonversi katalitik residu adalah kondisi operasi (temperatur, tekanan dan waktu reaksi), karakteristik bahan baku atau umpan (kandungan karbon, hidrogen dan heteroatom) dan katalis (jenis, luas permukaan dan jumlah katalis) yang digunakan.

Penelitian ini difokuskan pada pengkajian pengaruh temperatur dan waktu reaksi terhadap distribusi produk up-grading residu (distilat, gas hidrokarbon, dan liquid bottom) serta konsumsi gas $\mathrm{H}_{2}$ melalui hidrokonversi katalitik dengan menggunakan fasilitas lab-scale reaktor kapasitas 1 liter tipe batch.

\section{Bahan Dan Metode}

\section{Residu minyak bumi}

Residu yang digunakan dalam penelitian ini adalah jenis short residue yang diperoleh dari Unit Pengolahan Pertamina UP III, Plaju, Palembang.

Pada kilang pengolahan Pertamina, short residu merupakan salah satu produk bawah (bottom product) dari kolom distilasi vakum dengan titik didih di atas $540^{\circ} \mathrm{C}$ yang tidak dapat diolah lagi dan biasanya dijual sebagai LSWR (Low Sulphur Waxy Residue).

Hasil analisis proksimat dan ultimat serta spesifikasi residue tersebut ditunjukkan pada Tabel 1 dan Tabel 2. Sedangkan diagram alir produk residu tersebut ditunjukkan pada Gambar 1.

Tabel 1. Analisis Proksimat dan Ultimat Short Residue

\begin{tabular}{|l|r|}
\hline \multicolumn{1}{|c|}{ Parameter } & Nilai \\
\hline Proksimat dan Ultimat & \\
(\% as receive) & 0,21 \\
Moiture & 0,06 \\
Abu & 86,41 \\
Karbon & 11,28 \\
Hidrogen & 0,09 \\
Nitrogen & 0,08 \\
Total Sulfur & 1,87 \\
Oksigen & \\
& \\
Fraksi Distilat (\% berat) & 0,21 \\
H2O & $<0,10$ \\
LO(C5- $\left.180^{\circ} \mathrm{C}\right)$ & 15,67 \\
MO $\left(180-300^{\circ} \mathrm{C}\right)$ & 17,46 \\
HO $\left(300-420^{\circ} \mathrm{C}\right)$ & 66,66 \\
Bottom $\left(+420^{\circ} \mathrm{C}\right)$ & \\
Hasil analisis Lab. Karakteristik, B2TE, PUSPIPTEK, Serpong
\end{tabular}

Tabel 2. Spesifikasi dari Short residu

\begin{tabular}{|l|c|}
\hline Titik didih $\left({ }^{\circ} \mathrm{C}\right)$ & $540 \pm$ \\
Spesific Gravity ${ }^{\circ} \mathrm{C}$ & $0,9525-0,9854$ \\
API gravity & $17,1-12,1$ \\
Sulfur, \%wt & 0,250 \\
Redwood Viscosity & $696-951$ \\
\hline
\end{tabular}

Hasil analisis Lab. Pertamina, PuloGadung

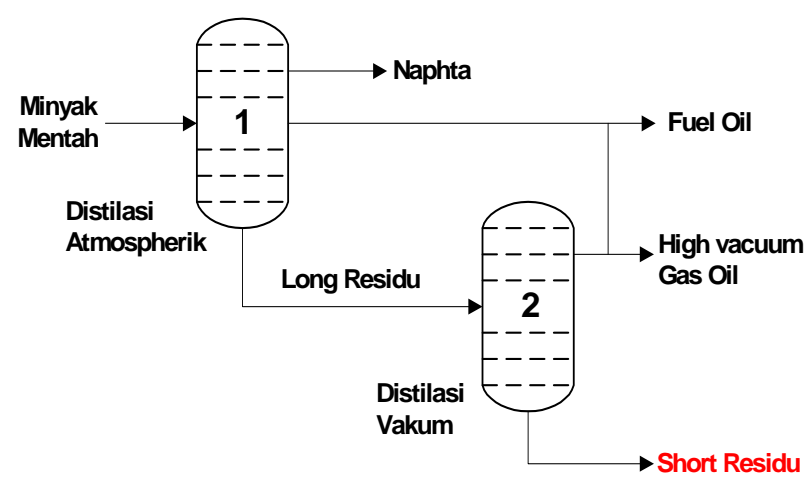

Gambar 1. Diagram alir produk residu

\section{Katalis}

Katalis yang digunakan dalam penelitian ini adalah katalis Limonit Soroako, Sulawesi Selatan Adapun komposisi unsur dan hasil analisis fraksi distilasi dari katalis tersebut dapat dilihat pada Tabel 3 dan Tabel 4. 
Tabel 3. Komposisi unsur katalis Limonit

\begin{tabular}{|c|c|c|c|c|c|c|c|c|}
\hline \multicolumn{9}{|c|}{$\%$ berat basis kering } \\
\hline $\mathrm{Fe}$ & $\mathrm{Al}$ & $\mathrm{Si}$ & $\mathrm{Ni}$ & $\mathrm{Cr}$ & Co & $\mathrm{Mg}$ & $\mathrm{Na}$ & $\mathrm{Ca}$ \\
\hline 46,97 & 3,35 & 2,64 & 1,29 & 0,81 & 0,09 & 0,08 & 0,04 & 0 \\
\hline
\end{tabular}

Tabel 4. Fraksi Distilasi katalis Limonit

\begin{tabular}{|c|c|c|c|c|c|}
\hline \multicolumn{2}{|c|}{ Rasio Slurry } & \multicolumn{4}{|c|}{ Fraksi (\% berat) } \\
\hline \% Padat & \% Cair & L O & M O & $\mathrm{H} \mathrm{O}$ & $\mathrm{H}_{2} \mathrm{O}$ \\
\hline 25,58 & 74,42 & 0,52 & 28,60 & 70,00 & 0,88 \\
\hline
\end{tabular}

Hasil analisis Lab. Penc. Batubara, P3TKKE-BPPT

Katalis ini dipilih karena telah menunjukkan performansi yang lebih baik disbanding dengan jenis katalis besi yang lain ${ }^{[5]}$. Sebelum digunakan katalis tersebut terlebih dahulu dipreparasi dalam bentuk bubur (slurry), dan selanjutnya katalis dikeringkan pada suhu $105^{\circ} \mathrm{C}$ selama 3 jam (sampai berat konstan). Setelah kering, katalis tersebut dicampur dengan pelarut heavy oil solvent $\left(300-420^{\circ} \mathrm{C}\right)$ dengan perbandingan tertentu, kemudian digiling dalam tower mill dengan bantuan zirconia ball selama 4 jam pada perputaran $1000 \mathrm{rpm}$, sehingga didapat katalis dengan ukuran sekitar 0.5 - 0.8 :m yang berbentuk suspensi koloidal. Variasi ukuran diameter partikel di bawah sub micron $(<1$ :m) tidak mempunyai pengaruh yang signifikan terhadap yield produk pencairan batubara muda.

\section{Promotor katalis}

Sulfur serbuk (98\%) digunakan sebagai promotor katalis, dalam reaksi perengkahan short residue berfungsi untuk membentuk fase aktif dari katalis dalam bentuk kristal pyrrhotite $\left(\mathrm{Fe}_{1-\mathrm{x}} \mathrm{S}\right)$, dimana X adalah 0 sampai 0.125.(Pollackand and Splitler, 1981)

\section{Gas reaktan}

Gas yang digunakan dalam penelitian ini adalah hidrogen dan nitrogen. Hidrogen $\left(\mathrm{H}_{2}\right)$ dipakai sebagai gas reaktan untuk reaksi, sedangkan nitrogen $\left(\mathrm{N}_{2}\right)$ diperlukan untuk membersihkan ruangan udara di dalam autoclave dan untuk menurunkan konsentrasi oksigen di dalam udara, agar tidak menyebabkan ledakan jika kontak dengan gas hidrogen.

\section{Metode pengujian}

Secara garis besar metode pengujian dibagi menjadi tiga tahap yaitu reaksi perengkahan short residue dalam autoclave, distilasi vakum produk cair dan analisis produk gas menggunakan gas khromatographi. Kondisi reaksi pengujian dapat dilihat pada Tabel 5.

Tabel 5. Kondisi reaksi pengujian

\begin{tabular}{|l|c|}
\hline \multicolumn{1}{|c|}{ Parameter } & Nilai \\
\hline Sulfur/Fe [rasio atom] & 2 \\
Katalis [wt\% on daf as Fe] & 1 \\
Jumlah $\mathrm{H}_{2}$ [wt\% on daf] & $>10 \%$ \\
Tekanan awal $\mathrm{H}_{2}$ [MPa] & 12 \\
Temperatur reaksi [ ${ }^{\circ} \mathrm{C}$ ] & $430,450,470$ \\
Waktu reaksi [menit] & $30,60,90$ \\
\hline
\end{tabular}

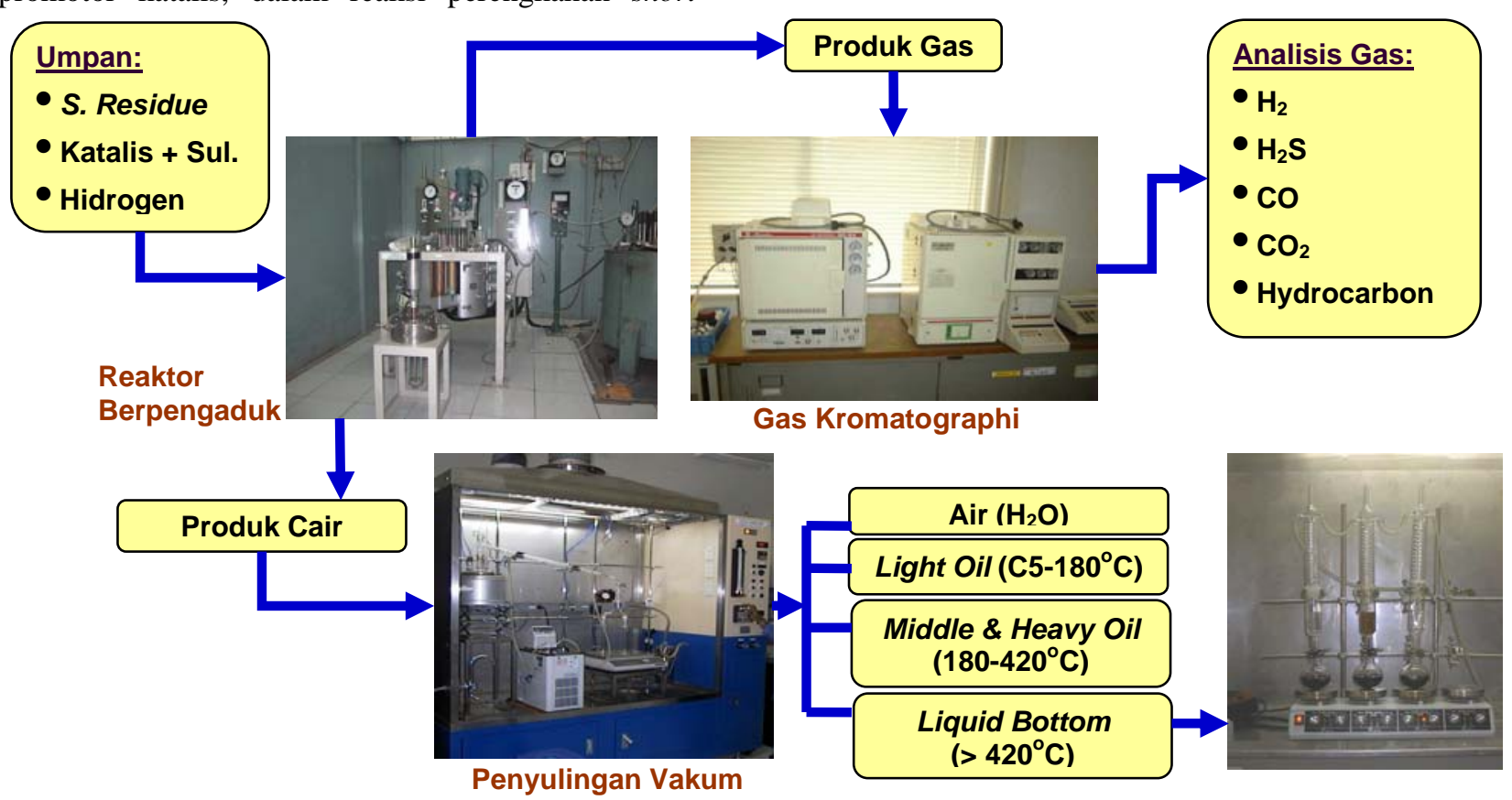

Gambar 2. Skema metode pengujian, peralatan dan analisis 
Perengkahan dilakukan pada reaktor autoclave yang berkapasitas 1 liter tipe batch yang dilengkapi pemanas (electric furnace window type) dengan kecepatan pemanasan $284{ }^{\circ} \mathrm{C} / \mathrm{jam}$ dan pengaduk (inductive agitator) dengan kecepatan $1000 \mathrm{rpm}$.

Setelah reaksi, produk cairan dipisahkan dengan menggunakan distilasi vakum untuk mendapatkan fraksi $\mathrm{H}_{2} \mathrm{O}$, fraksi minyak $\mathrm{C}_{5}$ dengan titik didih $\mathrm{C}_{5}-420^{\circ} \mathrm{C}$ dan fraksi liquid bottom (LB) dengan titik didih di atas $420^{\circ} \mathrm{C}$. Sedangkan produk gas diambil pada tiga kondisi tekanan autoclave yang mewakili yaitu 5, 3 dan $1 \mathrm{MPa}$. Analisis gas untuk masing-masing kondisi tersebut dilakukan dengan menggunakan gas kromatographi.

Konsentrasi gas $\mathrm{H}_{2}$, CO dan $\mathrm{CO}_{2}$ dianalisis dengan menggunakan Shimazdu GC-8A, Thermal Conductivity Detector dengan kolom dioctyl phtalete $4 \mathrm{mx} 3 \varnothing$, temperatur $100{ }^{\circ} \mathrm{C}$ dan argon sebagai gas carrier. Konsentrasi gas hidrokarbon $\left(\mathrm{C}_{1}-\mathrm{C}_{4}\right)$ dianalisis dengan menggunakan Yanaco GC-2800, Flame Ionization Detector dengan kolom porapak-Q $2 \mathrm{mx} 3 \varnothing$, temperatur $140{ }^{\circ} \mathrm{C}$ dan nitrogen sebagai gas carrier. Sedangkan analisis gas $\mathrm{H}_{2} \mathrm{~S}$ dengan menggunakan tube gas analyzer, Gastec Dragger. Semua yield ditentukan dalam basis berat kering bebas abu dari umpan short residue. Skema metode pengujian, peralatan dan analisis ditunjukkan pada Gambar 2.

\section{Hasil Dan Pembahasan}

\section{Pengaruh temperatur terhadap distribusi produk}

Pola hasil perhitungan distribusi produk dan konsumsi gas hidrogen pada berbagai temperatur reaksi ditunjukkan pada Tabel 6. Proses konversi hidro katalitik short residue menghasilkan produk distilat (LO, MO, dan $\mathrm{HO}$ ), produk gas hidrokarbon $\left(\mathrm{C}_{1}-\mathrm{C}_{4}\right), \mathrm{H}_{2} \mathrm{O}$ dan bottom. Produk gas $\mathrm{CO}+\mathrm{CO}_{2}$ tidak terdeteksi oleh GC-FID, dimana diduga karena rendahnya kandungan oksigen short residue $(1,87 \%$ berat DAF). Pembentukan CO dan $\mathrm{CO}_{2}$ sendiri sangat dipengaruhi oleh kandungan oksigen.

Tabel 6. Distribusi produk pada berbagai temperatur ( $\mathrm{P}$ awal $\mathrm{H}_{2}=12 \mathrm{MPa}, \quad=60$ menit)

\begin{tabular}{|l|r|r|r|}
\hline Temp. Reaksi (deg.C) & \multicolumn{1}{|c|}{430} & \multicolumn{1}{|c|}{450} & \multicolumn{1}{c|}{470} \\
\hline Umpan Bahan (gram) & & & \\
Short Residue & 107,09 & 107,09 & 107.09 \\
Katalis & 10,58 & 10.58 & 10,58 \\
Sulfur serbuk & 1,30 & 1,30 & 1,30 \\
Prod. (\%berat DAF) & & & \\
LO (Light Oil) & 2,98 & 13,42 & 12,08 \\
MO (Middle Oil) & 28,05 & 43,87 & 51,51 \\
HO (Heavy Oil) & 17,51 & 25,73 & 20,33 \\
Bottom & 49,82 & 14,25 & 16,62 \\
CO+CO & t.d & t.d & t.d \\
Hidrokarbon $\left(\mathrm{C}_{1}-\mathrm{C}_{4}\right)$ & 3,40 & 4,96 & 3,78 \\
Konsumsi $\mathrm{H}_{2}$ & 1,99 & 2,23 & 3,10 \\
\hline
\end{tabular}

=: waktu reaksi t.d $=$ tak terdeteksi
Perolehan gas hidrokarbon dari konversi short residue $\left(\mathrm{CH}_{4}, \mathrm{C}_{2} \mathrm{H}_{6}, \mathrm{C}_{3} \mathrm{H}_{8}\right.$ dan $\left.\mathrm{C}_{4} \mathrm{H}_{10}\right)$ mengalami peningkatan yang tidak signifikan dari temperatur $430^{\circ} \mathrm{C}\left(3,40\right.$ \%berat DAF) ke temperatur $450^{\circ} \mathrm{C}(4,69$ \%berat DAF). Sedangkan pada temperatur $470^{\circ} \mathrm{C}$ relatif mengalami penurunan, yaitu sebesar 3,78 \%berat DAF.

Gas hidrokarbon merupakan hasil perengkahan termal dan hidrogenasi fraksi minyak ringan sehingga dengan temperatur yang lebih tinggi akan dihasilkan gas hidrokarbon yang lebih banyak.

Menurut Gray pembentukan gas sangat dipengaruhi oleh faktor waktu dan temperatur proses. Rantai C-C dari fraksi minyak ringan akan pecah pada temperatur tinggi $\left(>420^{\circ} \mathrm{C},<470{ }^{\circ} \mathrm{C}\right)$ menghasilkan radikal bebas yang selanjutnya bereaksi dengan gas hidrogen melalui bantuan katalis membentuk gas hidrokarbon. Oleh karena itu peningkatan temperatur akan meningkatkan perolehan produk gas hidrokarbon. Namun temperatur yang sangat tinggi $\left(470^{\circ} \mathrm{C}\right)$ dapat mengurangi perolehan gas hidrokarbon karena adanya reaksi polimerisasi. Peningkatan perolehan distilat secara signifikan terjadi pada temperatur $430^{\circ} \mathrm{C}(48,55 \%)$ menjadi 83.03 \%berat DAF pada temperatur $450^{\circ} \mathrm{C}$. Temperatur yang lebih tinggi $\left(470^{\circ} \mathrm{C}\right)$ menghasilkan perolehan distilat yang relatif sama $(83,91 \%)$. MO mengalami peningkatan yang konstan untuk semua temperatur yaitu sebesar $28,05 \%\left(430^{\circ} \mathrm{C}\right), 43,87 \%\left(450^{\circ} \mathrm{C}\right)$ dan 51,51\% (470 $\left.{ }^{\circ} \mathrm{C}\right)$. Sedangkan LO mengalami peningkatan pada temperatur $430{ }^{\circ} \mathrm{C}(2,98 \%)$ menjadi $13,42 \%$ pada 450 ${ }^{\circ} \mathrm{C}$, selanjutnya relatif konstan pada $470^{\circ} \mathrm{C}$ yaitu sebesar 12,08\%berat DAF. Untuk HO mengalami peningkatan pada temperatur $430^{\circ} \mathrm{C}(17,51 \%)$ menjadi 25,73\% pada $450{ }^{\circ} \mathrm{C}$ dan mengalami penurunan pada temperatur $470{ }^{\circ} \mathrm{C}$ yaitu sebesar 20,33\%berat DAF. Peningkatan temperatur akan menunjukkan terjadinya perengkahan termal, disosiasi gas hidrogen dan stabilisasi radikal bebas melalui reaksi hidrogenasi sehingga perolehan distilat meningkat. Penurunan HO pada $470^{\circ} \mathrm{C}$ menunjukkan terjadinya perengkahan lanjut fraksi minyak berat menjadi MO.

Perolehan liquid bottom mengalami penurunan yang signifikan pada kenaikan temperatur $430^{\circ} \mathrm{C}$ (49,55\%) menjadi $14,25 \%$ pada $450^{\circ} \mathrm{C}$. Pada temperatur $470{ }^{\circ} \mathrm{C}$ relatif konstan, yaitu sebesar $16,62 \%$ berat DAF. Penurunan perolehan liquid bottom disebabkan pada temperatur rendah pemecahan rantai hidrokarbon pada cincin poli-aromatis belum sempurna, sehingga perolehan liquid bottom tinggi. Temperatur yang lebih tinggi $\left(450-470^{\circ} \mathrm{C}\right)$ memberikan peluang yang lebih besar bagi perengkahan termal cincin poliaromatis sehingga perolehan liquid botttom menurun tajam.

Konsumsi gas hidrogen meningkat dari 1,99\% $\left(430{ }^{\circ} \mathrm{C}\right)$ menjadi $2,33 \%\left(450{ }^{\circ} \mathrm{C}\right)$ dan $3,1 \%\left(470^{\circ} \mathrm{C}\right)$. Kenaikan temperatur meningkatkan perengkahan termal sehinggga menghasilkan semakin banyak radikal-radikal bebas. Untuk stabilisasi radikal bebas 
diperlukan atom $\mathrm{H}$ baik dari hidrokarbon sendiri maupun dari gas $\mathrm{H}_{2}$. Kenaikan temperatur juga akan meningkatkan aktifitas katalis, sehingga kerja katalis dalam melakukan disosiasi molekul gas hidrogen menghasilkan atom $\mathrm{H}$ bebas juga meningkat. Atom $\mathrm{H}$ bebas akan menstabilisasi radikal bebas, sehingga kenaikan temperatur akan meningkatkan konsumsi gas hidrogen.

\section{Pengaruh waktu reaksi terhadap distribusi produk}

Distribusi produk dan konsumsi gas hidrogen pada berbagai waktu reaksi ditunjukkan pada Tabel 7 . Gas hidrokarbon $\left(\mathrm{C}_{1}-\mathrm{C}_{4}\right)$ mengalami peningkatan tajam pada 60 menit sampai 90 menit yaitu 3,78\% menjadi $13,5 \%$ berat DAF. Untuk waktu reaksi 30 menit relatif sama dengan 60 menit, yaitu sebesar $4,30 \%$ berat DAF.

Waktu reaksi yang semakin lama akan mendorong lebih banyak terjadinya proses hidrokraking dan hidrogenasi senyawa hidrokarbon yang menghasilkan produk gas-gas hidrokarbon. Dengan temperatur reaksi yang tinggi $\left(470{ }^{\circ} \mathrm{C}\right)$ dan waktu yang semakin lama perengkahan termal terjadi lebih banyak baik pada cincin alifatis maupun aromatis.

Tabel 7. Distribusi produk pada berbagai waktu reaksi dengan tekanan awal $\mathrm{H}_{2} 12 \mathrm{MPa}$ dan temperatur reaksi $470^{\circ} \mathrm{C}$

\begin{tabular}{|l|r|r|r|}
\hline Waktu Reaksi (deg.C) & \multicolumn{1}{|c|}{30} & \multicolumn{1}{|c|}{60} & \multicolumn{1}{|c|}{90} \\
\hline Umpan Bahan (gram) & & & \\
Short Residue & 107,09 & 107,09 & 107,09 \\
Katalis & 10,58 & 10,58 & 10.58 \\
Sulfur serbuk & 1,30 & 1,30 & 1,30 \\
Produk (\%berat DAF) & & & \\
LO (Light Oil) & 4.56 & 12,08 & 12,42 \\
MO (Middle Oil) & 50.20 & 51,51 & 50,21 \\
HO (Heavy Oil) & 22,16 & 20,33 & 21,18 \\
$\mathrm{H}_{2} \mathrm{O}$ & 0.03 & 0.01 & 0.01 \\
Bottom & 20.83 & 16,62 & 7,35 \\
CO+CO & t.d & t.d & t.d \\
Hidrokarbon $\left(\mathrm{C}_{1}-\mathrm{C}_{4}\right)$ & 4,30 & 3,78 & 13,5 \\
Konsumsi $\mathrm{H}_{2}$ & 2,09 & 3,10 & 1,75 \\
\hline
\end{tabular}

Cat. t.d $=$ tak terdeteksi

Fraksi LO mengalami peningkatan signifikan pada waktu 30 menit (4,56\%)berat DAF sampai 60 menit $(12,08 \%$ berat DAF, tetapi relatif hampir konstan pada peningkatan waktu 90 menit $(12,42 \%)$ berat DAF. Fraksi distilat lainnya yaitu MO dan $\mathrm{HO}$ relatif konstan pada semua waktu yang diujikan. Semakin lama waktu reaksi maka peluang untuk melakukan perengkahan ikatan hidrokarbon semakin meningkat karena interaksi antara residu, katalis dan gas hidrogen semakin lama. Hal ini menyebabkan produk-produk ringan seperti distilat akan meningkat. Sedikitnya kenaikan LO dan cenderung konstannya MO dan HO disebabkan adanya dekomposisi termal lanjutan dari fraksi distilat membentuk fraksi gas.
Liquid bottom mengalami penurunan yang signifikan terhadap waktu reaksi yaitu pada 30 menit (20,83\%), 60 menit (16,62\%) dan 90 menit (7,35\%). Dengan semakin lamanya waktu reaksi maka peluang untuk melakukan perengkahan termal fraksi berat akan lebih besar sehingga jumlah fraksi berat mengalami penurunan. Perengkahan semakin banyak terjadi pada molekul-molekul yang berat karena molekul tersebut punya lebih banyak ikatan. Hal tersebut mengakibatkan perolehan liquid bottom akan semakin menurun dengan bertambahnya waktu reaksi.

Gas hidrogen yang terkonsumsi mengalami kenaikan dengan bertambahnya waktu reaksi. Namun hasil ini terjadi sampai pada 60 menit yaitu sebesar 3,10\% berat DAF, selanjutnya mengalami penurunan pada 90 menit sebesar $1,75 \%$ berat DAF, sedangkan konsumsi $\mathrm{H}_{2}$ pada 30 menit sebesar 2,09\% berat DAF.

Hasil ini terlihat kontradiktif karena waktu reaksi yang semakin lama seharusnya kebutuhan atom $\mathrm{H}$ bebas dari gas $\mathrm{H}_{2}$ untuk stabilisasi radikal bebas semakin banyak. Diduga kebutuhan atom $\mathrm{H}$ untuk stabilisasi radikal bebas telah dipenuhi sendiri oleh short residu, dimana memiliki kandungan hidrogen yang cukup tinggi (11,31\%berat DAF), sehingga pada waktu perengkahan dihasilkan atom $\mathrm{H}$ bebas yang cukup.

Faktor lain yang diduga menyebabkan penurunan konsumsi gas hidrogen adalah penurunan aktifitas katalis. Peran katalis ini adalah melakukan disosiasi katalitik gas $\mathrm{H} 2$ sehingga menghasilkan atom-atom $\mathrm{H}$, selanjutnya atom $\mathrm{H}$ ini menginduksi pemecahan ikatan dan stabilisasi radikal bebas.

\section{Distribusi produk distilasi}

Tabel 8 menunjukkan hasil distilasi vakum bahan baku (short residue sebelum proses upgrading) dan produk up-grading pada berbagai kondisi operasi yang diujikan.

Tabel 8. Hasil Distilasi Produk Up-grading pada Berbagai Kondisi Operasi

\begin{tabular}{|c|c|c|c|c|c|}
\hline Kondisi & \multicolumn{5}{|c|}{ Komposisi Fraksi (Persen Berat) } \\
\cline { 2 - 6 }$\left[{ }^{\circ} \mathrm{C}-\right.$ menit $]$ & LO & MO & HO & Bottom & $\mathrm{H}_{2} \mathrm{O}$ \\
\hline $430-60$ & 2,81 & 27,69 & 20,91 & 47,14 & 1,45 \\
$450-60$ & 12,78 & 43,15 & 28,22 & 14,83 & 1,02 \\
$470-30$ & 4,30 & 48,49 & 25,44 & 20,81 & 0,96 \\
$470-60$ & 11,06 & 48,86 & 23,45 & 14,83 & - \\
$470-90$ & 12,82 & 51,43 & 26,55 & 9,20 & - \\
Bahan Baku & $<0.1$ & 15.67 & 17.46 & 66.66 & 0.21 \\
\hline
\end{tabular}

Tampak terjadi peningkatan yang signifikan kandungan minyak distilat (LO,MO,HO) semua produk pada berbagai kondisi operasi dibandingkan dengan bahan baku. Peningkatan kualitas yang paling baik terjadi pada kondisi operasi $470^{\circ} \mathrm{C}-90$ menit dengan kandungan LO 12,82 \%berat, MO 51,43 \%berat, HO 26,55 \%berat dan bottom 9,20 \%berat. Distilat merupakan fraksi yang sangat diharapkan pada setiap proses upgrading. Semakin banyak fraksi 
distilat (LO,MO dan HO) yang dihasilkan maka proses upgrading dianggap semakin baik.

\section{Kesimpulan}

a) Kenaikan kondisi operasi (temperatur dan waktu reaksi) dapat meningkatkan perolehan distilat (minyak) pada hidrokonversi katalitik residu minyak bumi.

b) Kenaikan temperatur reaksi menyebabkan perolehan liquid bottom yang dihasilkan semakin sedikit, karena terkonversi menjadi fraksi distilat dan fraksi gas.

c) Waktu reaksi yang semakin lama menunjukkan adanya peningkatan fraksi distilat dan fraksi gas.

d) Pelepasan gas-gas hidrokarbon produk hidrokonversi katalitik residu minyak bumi sangat dipengaruhi oleh temperatur reaksi dan waktu reaksi.

\section{Ucapan Terima Kasih}

Penulis mengucapkan terima kasih kepada manajemen Laboratorium Pencairan Batubara, P3TKKE-BPPT, PUSPIPTEK, Serpong, yang telah memberikan dukungan hingga terselesaikannya penelitian ini dengan baik.

\section{Daftar Pustaka}

Indartono S.Y., (2005) "Krisis Energi di Indonesia: Mengapa dan Harus Bagaimana”, Inovasi Online Vol.5/XVII/November.

Gray, Murray R., (1994), “Upgrading Petroleum Residue and Heavy Oils”, Marcel Dekker Inc., New York,

Gray, Murray R., Mc. Caffrey, W., and William C., (2002), "Role of Chain and Olefin Formation in Cracking, Hydroconversion and Coking of Petroleum and Bitumen Fraction”, Energy \& Fuel.

Stanford, E.C., (1993) "Mechanism of Coke Prevention by Hydrogen Cracking during Residuum Hydro-cracking”, Prepr. Div. Petrol. Chem, American Chemical Society.

Sugeng dan Rahmat, (2004), “Laporan Akhir Penelitian Mahasiswa di Lab. Penc. Batubara P3TKKE-BPPT"'.

S. S. Pollackand, C. A. Splitler (1981), "Iron content of pyrrhotites produced in continuous liquefaction units”, American Mineralogist, Volume 66, pages 1258-1262. 